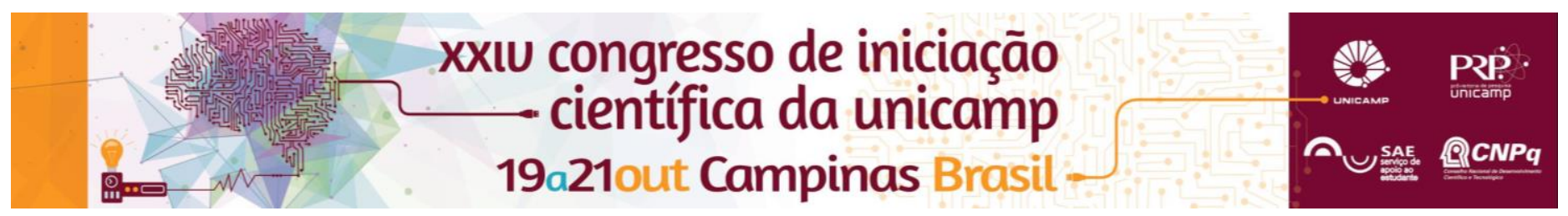

\title{
CourseViewer: integração da ferramenta a sistemas de gerenciamento acadêmico e comparação de históricos escolares.
}

\section{Matheus Gonçalves da Silva (IC)}

\section{Resumo}

O uso de gráficos interativos para representar históricos escolares e catálogos de cursos tem sido a principal estratégia utilizada pelo software CourseViewer para auxiliar alunos, professores e coordenadores de cursos universitários a analisar informações sobre disciplinas, como créditos e pré-requisitos. Dentre suas limitações, destaca-se que a arquitetura atual do software dificulta sua integração com sistemas externos e o software não permite comparar um conjunto de históricos escolares. Neste sentido, este projeto objetiva implementou uma camada de integração que possibilite sua futura integração a sistemas externos, implementou-se também um método de visualização que permite a comparação de diversos históricos escolares.

\section{Palavras-chave:}

Visualização, camada de integração, comparação de históricos escolares.

\section{Introdução}

O CourseViewer ${ }^{1}$ é uma ferramenta que permite visualizar catálogos de cursos (Figura 1) e históricos escolares.

Porém, sua arquitetura atual dificulta sua integração com sistemas externos, como por exemplo o da própria DAC, além disso, não possibilita a comparação de históricos escolares. Assim, esse projeto implementou uma camada de integração com sistemas internos, foi criado um sistema baseado na arquitetura REST para que fosse possível realizar testes para validar a camada. Foi implementado também uma técnica de visualização de dados baseada em pontos. Para representação de dados multidimensionais.

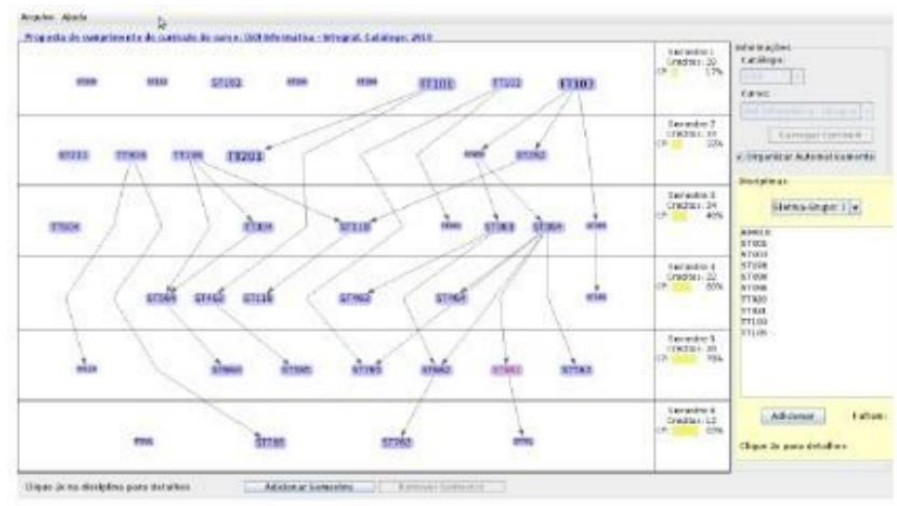

Figura 1. Interface Gráfica do CourseViewer

\section{Resultados e Discussão}

A ferramenta utiliza de arquivos XML 2 definidos por Ferreira3, para realizar a manipulação destes arquivos foi utilizada uma ferramenta que permitisse converter arquivos em classes. Através dessa conversão, a manipulação dos dados foi simplificada. Após ter se definido a manipulação dos arquivos, foi necessário criar uma camada de integração com sistemas externos, para isso, foi criado um serviço na arquitetura REST que utiliza da arquitetura cliente-servidor para que os dados sejam disponibilizados independente da linguagem.

A segunda fase do projeto teve como objetivo implementar uma técnica de comparação de históricos. A visualização de informação (infoViz3 ) tem como foco proporcionar ao usuário um entendimento maior dos dados. Históricos possuem diversas variáveis a serem caracterizadas, devido a isso, a técnica de visualização multidimensional baseada em pontos foi aplicada para que $\mathrm{n}$ variáveis fossem capazes de serem representadas em um plano 2D.

\section{Conclusões}

A criação de uma camada de integração no CourseViewer é uma etapa importante já que será possível obter dados corretos sobre cursos direto da própria universidade. A criação de um método de comparação de catálogos ajudará coordenadores na tomada de decisão através da representação de semelhança entre os históricos.

\section{Agradecimentos}

Agradecimentos à Fapesp pelo financiamento do projeto e ao Celmar pelo apoio no desenvolvimento do mesmo.

1 Silva, G. C.; Visualização de informação: Introdução e influencias de IHC. Capítulo 4. SIBGRAPI.

2 Shixia Liu, Weiwei Cui, YingcaiWu, Mengchen Liu, A survey on information visualization: recent advances and challenges. Publicado online.

${ }^{3}$ Ferreira, M. H. (2015). Integração da ferramenta CourseViewer a sistemas de gerenciamento acadêmico. Relatório Parcial submetido à PRP/Unicamp. Não publicado.

1 Zinsly, T. (2014) "Redefinição e implementação de arquitetura do software Course Viewer". Trabalho de Conclusão de Curso, Faculdade de Tecnologia, Universidade Estadual de Campinas. 